\title{
Improving Basic Composition Skills of Secondary Level Students in the Sri the Lankan School Context: An Action Research
}

\author{
Hashini Abeysena \\ School of Education, Deakin University, Australia
}

\begin{abstract}
This is an action research based on a government school located in the Western province in Sri Lanka on Improving ESL Composition Skills of Secondary Level Students. Literature shows poor composition skills is a common issue among the junior secondary learners ranging from classroom level to national level G.C.E. Ordinary Level examination. Thus, the current study explores the issue of low performance in writing based questions of the secondary ESL students in a type $C$ school in the western province. A sample of forty (40) students from grade ten (10) studying English as a Second Language (ESL) was taken to the study from convenience sampling. Initially semistructured interviews were conducted on the matter investigated with the principal, a few students and the two ESL teachers in grade ten of the selected school. Since their perceptions on the matter were merely taken to activate their schemata for the study, the data were not considered for analysis. A questionnaire was administered among the students, and then a pre-test and a post-test were given on an ESL composition task resembling an item in the $O / L$ English language paper during the intervention process. Their scores were collected and the mean difference was recorded. A slight improvement was seen after utilizing the process writing approach via VARK model.
\end{abstract}

\section{Introduction}

English language is considered a lingua franca that is taught in many Anglophonic countries as a second language/foreign/ additional language. In Sri Lanka, English language is taught as a second language (ESL) at schools from grade three to thirteen for decades. Following independence in 1948, English language was taught as a second language at all schools and therefore, most Sri Lankans had an opportunity to learn English from childhood. School education therefore plays a vital role in developing English communication skills of ESL students.

However, the Examination Department and the Ministry of Education (MOE) in Sri Lanka have notified a lowest pass rate for English language at the GCE O/L examination for several years. For instance, in $2014,52.14$ percent of students who sat the O/L English examination failed - the highest failing rate compared to all other subjects [13]. Despite a slight increase in the pass rate of English during the period from 2010 to 2015 (See Appendix 01), current ESL education has failed to achieve the $50 \%$ pass rate. According to literature, most students have failed to answer the questions that test students' composition skills. According to the English Language Evaluation Report [11] based on the $2015 \mathrm{O} / \mathrm{L}$ examination results, students were weaker in answering tests/items which examined their writing skills. For example, students have scored very low marks for test 08 and test 16 which are the main writing tasks available in question papers 1 and paper 2 respectively. Considering the distribution of marks for test 08 and test 16 (See Figure 02), it seems that only $17 \%$ and $12 \%$ of students were able to score over $50 \%$ at the national G.C.E.O/L English paper.
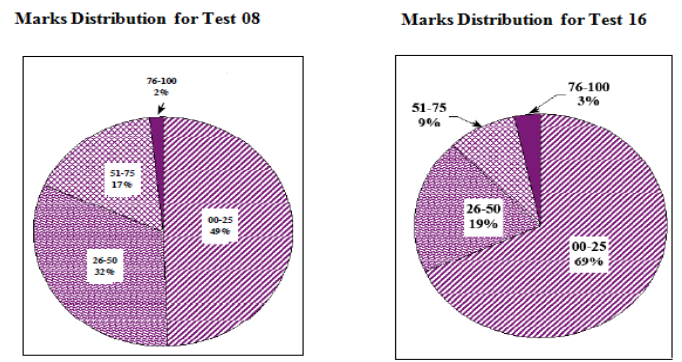

Figure 1. Marks Distribution for Test 08 and Test 16 [11]

In fact, according to most of the participants, Test 8 is a free writing task that seems quite difficult for the students. The students have displayed their common weaknesses in providing accurate language in this writing task, since they have not been trained to express themselves accurately in the target language respecting the mechanics of writing effectively.

After an overview of literature, a gap was found on applying various pedagogical methods/techniques to improve composition skills of the students in the GCE O/L classes (junior secondary) in the Sri Lankan context. Hence, as a part of the researcher's Postgraduate Diploma in Education, an action research was undertaken in her practicum school. As a result, this paper is based on her findings during a period of three months at the type $\mathrm{C}$ school (grade 1 to 11) located in the Western Province of Sri Lanka, 
in which the researcher taught ESL to grade 10 students. The sample was chosen with the objective of improving their basic mechanics of writing via process writing with VARK model that will be a precursor for achieving further skills in composition, i.e., the ESL students' writing questions at school and national level examinations as in picture description, parallel writing, paragraph writing, note or notice in English language Paper 1. In Paper 2, there are composition questions such as formal or informal letter writing, graph description or essay (narrative, personal, descriptive, argumentative etc.).

\section{Aims and Objectives}

The research's significant aims are to examine existing pedagogical practices reflecting theory and application in developing writing skill in ESL students and identify best practices for developing basic composition skills to bridge the gap between theory and application in secondary ESL education. Most important objectives are to construct grammatically correct sentences in a passage/text, to identify, analyze and rectify the morpho-syntactic and morpho-semantic errors used in sentences, to match topic sentences and concluding sentences to the given paragraphs of a passage/text, and to maintain cohesion and coherence between sentences and paragraphs.

Most of the ESL students in the sample were unable to use basic mechanics of writing to construct meaningful sentences with accurate morphosemantics and morpho - syntactic and other cohesive devices. Considering these evidential factors, the researcher understood the need to address the identified gaps and foster improvement in writing skills. .

Furthermore, it is important to see if the teaching and learning of L2 equal the standards depicted in the national curricular for secondary grades. In this light, according to grade 10 Teacher's Guide for English language, [12], significant learning outcomes related to composition skills of learners include the ability of learners to use mechanics of writing with understanding and to use English grammar for the purpose of accurate and effective communication (See Appendix 02). Thus, the current study attempts to achieve these learning outcomes via an effective pedagogical technique as described below.

\section{Significance of the Study}

Development of varied analytical and creative skills is also necessary for higher order skills improvement, as interpreted in the contemporary concept of education and in the Sri Lankan secondary school context. Writing skills in ESL are useful not only for academic success of the learners, but also for their upward social mobility in contemporary neoliberal society. Therefore, it is essential to lay a good foundation at school to develop their basic composition skills.

\section{Limitations}

This study focused on 40 students aged 15, who study English as a Second Language in the chosen type $\mathrm{C}$ school, from primary to junior secondary. Due to the small size of the sample, findings may not constitute an average sample of ESL student population studying at different types of schools. Further, the researcher (teaching ESL for the Teaching practicum of the Postgraduate Diploma in Education), had only about two and half months to carry out the research while teaching. Thus, the duration was not adequate to witness the long-term impact of the pedagogical intervention.

Further, students in the school show a generally very low performance in the English language. For ethical considerations, three students with extreme learning difficulties/differences (dyslexia and dysgraphia) were not considered as sample due to ethical considerations.

\section{Review of the Literature}

The review of literature includes research on various pedagogical approaches and tools to teach composition skills. Shaffleet et al [8] evaluated the different techniques to gain composition skills to communicate in English both in oral and written discourse and underpinned the importance of Composition skills in English. Moreover, grammar can be considered as one of the major elements essential for communication [5], [9], because meaning, logic and interest for reading a composition will be determined by the grammatical categories. Gottschalk [4] has emphasized use of grammar games to develop their language skills, including written discourse.

VARK model is an effective model to teach students about the use of grammar in English [10]. Term VARK is used to explain four sensory modalities called Visual, Aural and Oral, Read and Kinesthetic via which different language learners acquire language skills. Literature shows that common morpho-syntactic errors include flaws in the subject-verb accords, errors in the use determiners, pronouns and preposition errors [6]. Moreover, students' lack of attention to transition devices make them lose a good flow in their composition [7]. However, inadequate teaching-learning materials, L2 facilities and lack of confidence in learners typically cause them to make these errors continuously [1]. 


\section{Conceptual Framework}

Improving basic L2 composition skills of junior secondary students is the main objective of this research. Thus, it is essential to find whether best practices in writing are effectively practiced in teaching and learning of composition skills in the secondary level. For a comprehensive understanding of the conceptual framework, the key stages involved in the process are illustrated as follows.

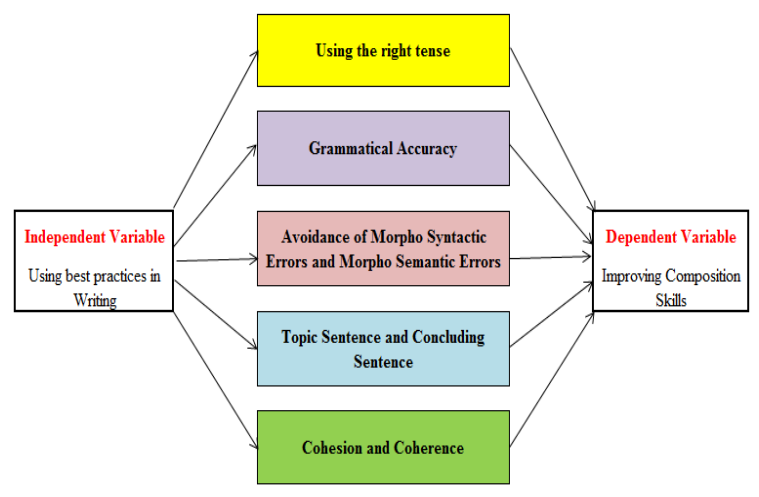

Figure 2. Conceptual Framework

\section{Methodology}

This research used mixed method of both quantitative and qualitative approaches for gathering data. As primary data collecting tools, a structured questionnaire, and an empirical study via a pedagogical intervention were utilized. To collect relevant secondary data, the writer has referred to journal articles. The sample size of this study is 40 students (both male and female students aged 15) in grade 10 at a type $\mathrm{C}$ school in the area called Ganemulla, Kadawatha, belonging to the Zonal Education Office in Mahara, Gampaha district, located in the western province of Sri Lanka. Convenience sampling was used as the method of sampling.

The researcher conducted a pretest with one class from the two grade 10 classes that the researcher was teaching. The particular class consisted of 43 ESL students, from whom 3 students were not considered for the study due to ethical reasons and severe learning differences (dysgraphia and dyslexia). The pretest was designed addressing the learning outcomes in the grade 10 syllabus regarding improving writing skills in compliance with the marking criteria of the English language paper at the national G.C.E.O/L. In general, language, content and format were considered in marking the pre-test scripts. By aligning with these criteria, and most importantly, by complying with the research objectives, the researcher analyzed their compositions on the given topics (similar to the ones given at the G.C.E O/L) under five specific areas: grammar, vocabulary, punctuation, cohesion and coherence. From the pre-test, surprisingly, all 40 students showed marks below $45 \%$. During the two and half months of teaching, the intervention was done after which the same test was conducted as the post-test with the same marking criteria.

Process writing approach was encouraged by the researcher during the intervention via utilization of VARK model. Students were given practice on various basic compositions based on process writing, which is divided into five stages as follows: Prewriting, drafting, composing, revising and editing. Students were instructed in all these stages to improve their writing mechanics via different activities as practiced in VARK model. Different learners were grouped under different learning style-based simple tasks that they were mostly comfortable with. In the pre-writing stage, students were trained to collect and gather ideas using strategies such as brain-storming and student discussions that were mainly led by peer learning group tasks upon their preferred learning style. In the drafting stage, they were asked to prepare a draft for the given topic in writing. They were instructed to limit their composition to 100 words and 3 paragraphs. In the composing style, they were to work appropriately in the given peer learning tasks, and later on individual activities. At the initial level, this was more group activities, whereas from the second week, once they understood the ways and means of engaging in the composition, they were encouraged to work individually, as a preparation for their O/L writing tasks. The teacher used classroom monitoring and facilitated their needs related to the basic mechanics of writing in a more student centered pedagogy. Accordingly, in revising and editing stages, the students were engaged in refining their work with peers and getting their feedback before the teacher's comments.

Moreover, VARK model is a pedagogical model recommended to teach the students about the use of mechanics of grammar mostly in writing [10]. The term VARK is used to explain the four sensory modalities called Visual, Aural and Oral, Read and Kinesthetic. Visual refers to graphical modes that the students prefer to use to learn as in maps, spider diagrams, graphs, flow charts related to the topic. Aural mode of teaching tasks were given to facilitate the learners who preferred activities done in terms of lecture mode with more teacher talking/explaining and group discussion. $\mathrm{R}$ refers to read or write, where learning materials varied from reports, essays and assignments, lists, diaries, and dictionaries (Feiming $\&$ Baume, 2006). Kinesthetic $(\mathrm{K})$ is the learning modality used with learners who prefer experience and practice to learn things using more physical actions/movements. 


\section{Instruments for data gathering}

Initially, semi-structured interviews were conducted with the school principal and the two English language teachers at school to activate their schemata of the phenomena investigated in the study, via which they are well informed about the study conducted with their students. However, their perceptions were not taken as data for the analysis. Questionnaires were administered by the researcher among the student participants. Close-ended Likert scaled questions were included in these questionnaires administered to get their perceptions on basic composition writing skills and the practical difficulties they face in such writing tasks. Since the researcher had to conduct two written exams (pre-test and post-test) during her teaching intervention to test students' writing skills, the question papers (pre-test paper and posttest paper) can be considered as data collecting instruments too.

\section{Analysis}

For the analysis of data, both quantitative and qualitative analytical methods were utilized. To analyze the numerical responses derived from closeended questions to comprehend the participants' perceptions, the researcher used both descriptive and inferential statistics. As descriptive statistics, mean, mode, median and standard deviations were recorded while correlations, coefficients were used as inferential statistics. Furthermore, descriptive statistics were used to analyze dispersion of responses derived from the questionnaires. Under inferential statistics, a Paired Sample T-Test was carried out, since it could accurately analyze if there was a statistical difference between the mean value of students' marks achieved in pre-test and post-test papers.

\subsection{Analysis of the Questionnaires}

In filling out these questionnaires, students had to put numerical responses (from 1 to 5) using the Likert scale weights as follows.

Table 1. Likert Scale and Weights

\begin{tabular}{|l|l|}
\hline Likert Scale & Weight \\
\hline Strongly Disagree & 1 \\
\hline Disagree & 2 \\
\hline Neutral & 3 \\
\hline Agree & 4 \\
\hline Strongly Agree & 5 \\
\hline
\end{tabular}

Basically, the questionnaire included 15 close ended questions with five Likert scaled options. These
15 questions were subdivided into 5 sections where each section included 3 sub questions. Numerical responses (weights) derived for each section in the questionnaire are presented using five column charts. In these column charts, $X$ axis reveals the five different Likert scale categories from 1-5 while Y axis represents the percentage of students' responses of each question.

9.1.1. Questionnaire Section 01 - Using the Right Tense in writing. The first three questions of the Questionnaire focused on the self-assessment of the students on their ability to use tense correctly in English. Knowledge of students on various tenses, their use of different tenses in writing and perceptions of the students to use the tenses accurately is evaluated from the first three questions of the questionnaire. Most students (30\%) have stated that they do not have enough knowledge on various tenses in English, whereas only $12 \%$ have said they have an adequate knowledge. These data show that lack of proper skill in using tenses accurately in composition has hindered their writing. Statistical measure of the values has been analyzed below.

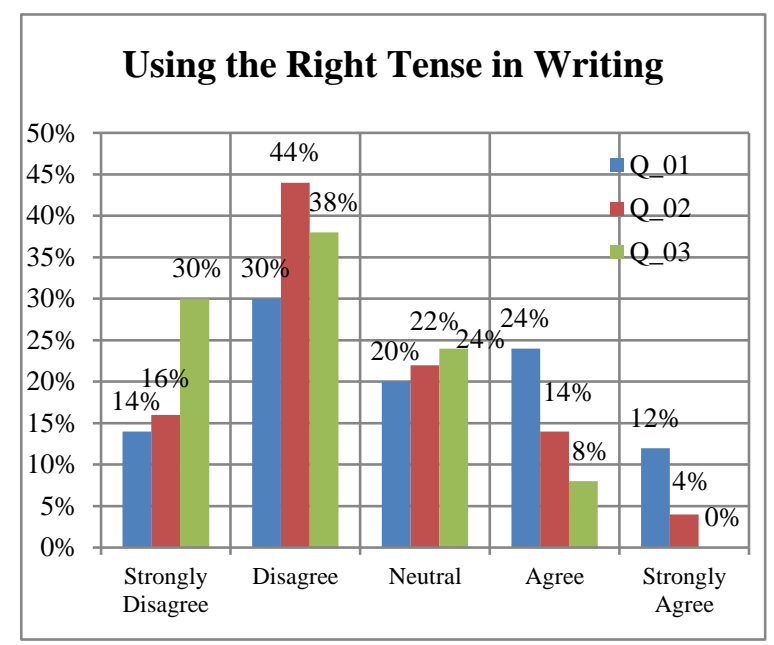

Figure 3. Using the Right Tense in Composition

Descriptive statistics of the above chart are presented below. It shows the mean and standard deviation of the three questions explored in the questionnaire.

Table 2. Using the Right Tense - Descriptive Statistics

\begin{tabular}{|c|c|c|l|}
\hline $\begin{array}{c}\text { Statistical } \\
\text { Measure }\end{array}$ & Q_01 & Q_02 & \multirow{2}{*}{ Q_03 } \\
\cline { 1 - 3 } Mean & 2.9 & 2.46 & 2.1 \\
\hline $\begin{array}{c}\text { Standard } \\
\text { Deviation }\end{array}$ & 1.26572 & 1.05386 & 0.93131 \\
\hline
\end{tabular}

9.1.2. Questionnaire Section 02: Grammatical Accuracy in Writing on Parts on Speech. Question 
number four to question number six focused on the grammatical accuracy of the students based on their understanding on parts of speech. Comprehensive knowledge of the students' basic grammar (parts of speech) was questioned by the fourth question. Data show that some of them are very satisfied with their comprehensive grammatical knowledge while some of them have shown a demand for more. Second question regards the revision in errors of parts of speech of the students after writing their composition. For instance, $32 \%$ of the participants disagreed that they have an adequate knowledge of grammar, whereas $8 \%$ stated that they attend to revision after a composition writing.

Descriptive statistics of the above chart are presented below. It shows the mean and standard deviation of the three questions explored in the questionnaire. Mean value of 2.86 has been recorded for that question, which demonstrates mixed reactions of the students. For instance, some of them are satisfied with their analytical revision of errors after writing while some have demanded more. Ironically, the majority of the students have confidence in the need to apply accuracy to their grammar in writing and their knowledge about it.

Descriptive statistics of the above chart are presented below. It shows the mean and standard deviation of the three questions explored in the questionnaire.

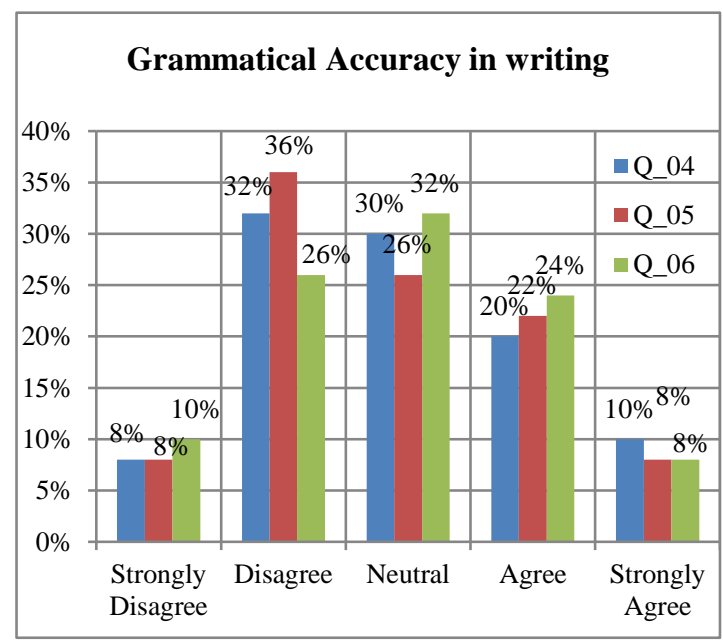

Figure 4. Grammatical Accuracy in Writing

Table 1. Grammatical Accuracy: Descriptive Statistics

\begin{tabular}{|c|c|l|c|}
\hline $\begin{array}{c}\text { Statistical } \\
\text { Measure }\end{array}$ & Q_04 & Q_05 & Q_06 \\
\hline Mean & 2.92 & 2.86 & 2.94 \\
\hline $\begin{array}{c}\text { Standard } \\
\text { Deviation }\end{array}$ & $\begin{array}{c}1.1219 \\
5\end{array}$ & $\mathbf{1 . 1 0 6 7 5}$ & $\mathbf{1 . 1 1 4 1}$ \\
\hline
\end{tabular}

9.1.3. Questionnaire Section 03: Avoidance of Morpho-syntactic and Morpho-Semantics Errors in writing. Third part of the questionnaire is focused on avoidance of morpho-syntactic and morphosemantic errors in writing. Questions number seven to nine are based on this aspect. In scrutinizing the percentages derived for question number seven, only some students have understood the relationship between the verbs and direct or indirect objects in a sentence. In other words, most of students do not know how verbs in a sentence determine the direct or indirect nature of the object. For this question, $4 \%$ and $22 \%$ of students respectively provided strongly agreed and agreed responses. Eighth question of the questionnaire is regarding the vocabulary of the students. Only $8 \%$ and $22 \%$ of the students accepted that they have good vocabulary in English. Knowledge of language rules in preparing sentences was focused from the ninth question. Most students indicated that they have mixed reactions. Apart from that, Gibbons [3] reveals that most students have failed to communicate their ideas effectively in written and oral discourse due to their inability to analyze their own morpho-syntactic and morphosemantic errors.

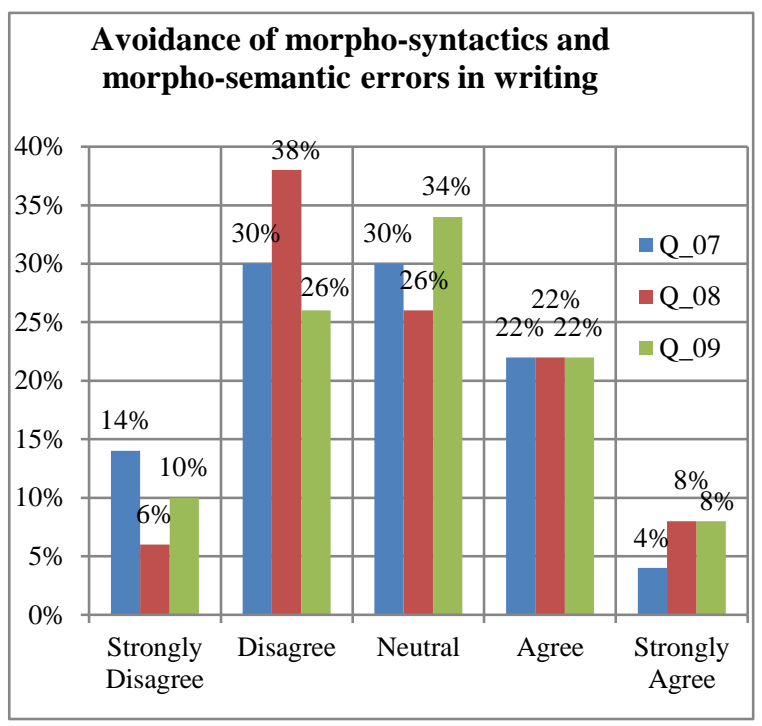

Figure 5. Avoidance of Morpho-syntactic and Morpho-Semantic Errors in writing

Descriptive statistics of the above chart are presented below. It shows the mean and standard deviation of these two questions explored in the questionnaire.

Table 4. Avoidance of Morpho-Syntactic and Morpho-Semantic errors: Descriptive Statistics

\begin{tabular}{|c|c|l|c|}
\hline Statistical Measure & Q_07 & Q_08 & Q_09 \\
\hline Mean & 2.72 & 2.88 & 2.92 \\
\hline Standard Deviation & 1.08872 & 1.08119 & 1.10361 \\
\hline
\end{tabular}


9.1.4. Questionnaire Section 04: Topic sentence and concluding Sentence. Fourth part of the questionnaire regards developing the topic sentence and concluding sentence in a paragraph in practicing compositions. None of the students have accepted that they can write the topic sentence concluding sentences correctly. According to Echevarria [2], topic sentence and concluding sentence in a composition are very important to communicate the message meaningfully to the reader. Since most of the students have failed to do so, it has become a huge barrier, along with the other related aspects in marking for them to score well in their writing in terms of language, grammar and format. The following chart shows that the students demonstrated negative perceptions to all questions with respect to the questions in this section.

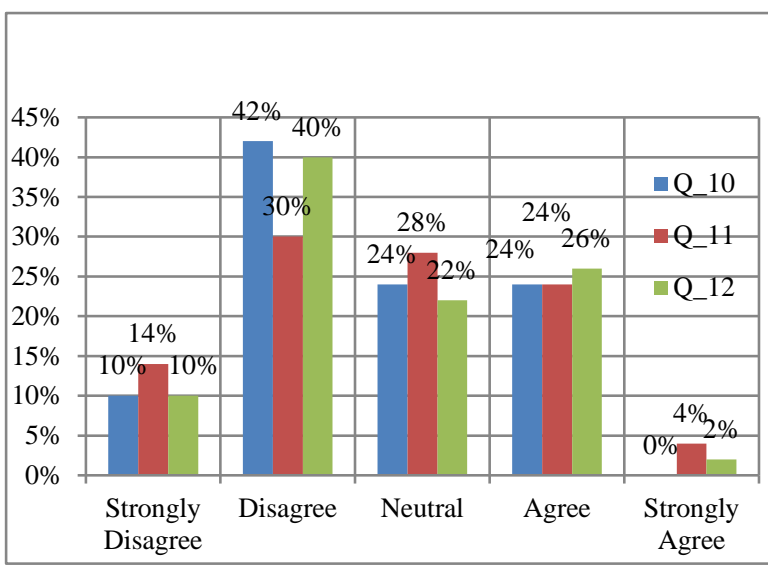

Figure 6. Topic sentence and concluding Sentence

Descriptive statistics of the above chart are presented below. It shows the mean and standard deviation of these two questions explored in the questionnaire.

Table 2. Topic Sentence and Concluding Sentence: Descriptive Statistics

\begin{tabular}{|c|c|l|c|}
\hline $\begin{array}{c}\text { Statistical } \\
\text { Measure }\end{array}$ & Q_10 & Q_11 & Q_12 \\
\hline Mean & $\mathbf{2 . 6 2}$ & $\mathbf{2 . 7 4}$ & 2.7 \\
\hline $\begin{array}{c}\text { Standard } \\
\text { Deviation }\end{array}$ & $\mathbf{0 . 9 6 6 5 8}$ & $\mathbf{1 . 1 0 3 0 6}$ & $\mathbf{1 . 0 3 5 1}$ \\
\hline
\end{tabular}

9.1.5. Questionnaire Section 05: Cohesion and Coherence. Question number 13, 14, and 15 are developed to test the students' perceptions on cohesion and coherence. For question 13 most of the students said that they are not fully aware of connecting sentences and arranging sentences properly. From the 15th question, their understanding of the structure of the essay is assessed. However, most of the students accepted their essays are neither well-structured nor well-communicated. For instance, this makes $50 \%$ of the majority who have negatively responded to that question.

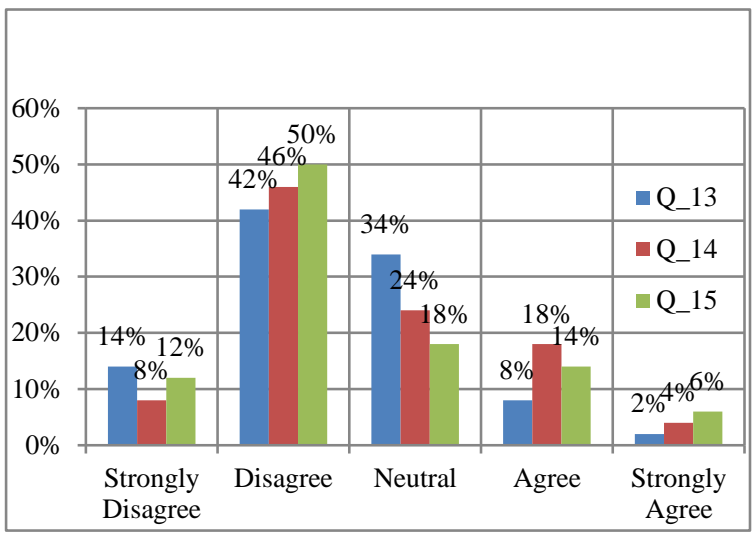

Figure 7. Cohesion and Coherence

Descriptive statistics of the above chart are presented below. It shows the mean and standard deviation of these two questions explored in the questionnaire.

Table 3. Cohesion and Coherence: Descriptive Statistics

\begin{tabular}{|c|c|l|c|}
\hline Statistical Measure & Q_13 & Q_14 & Q_15 \\
\hline Mean & 2.42 & 2.64 & 2.52 \\
\hline Standard Deviation & 0.90554 & 1.00529 & 1.07362 \\
\hline
\end{tabular}

\subsection{Comparison of pre-test and post-test marks}

After the intervention period of about two months following the VARK model via process writing approach, comparison between the pre-test and posttest results on basic composition writing skills was made as follows.

Table 4. Comparison of Pre-Test and Post-Test Scores of Students

\begin{tabular}{|l|l|l|l|}
\hline Student & $\begin{array}{l}\text { Pre-Test } \\
\text { Scores }\end{array}$ & $\begin{array}{l}\text { Post- } \\
\text { Test } \\
\text { Scores }\end{array}$ & Difference \\
\hline 1 & $37.20 \%$ & $44.00 \%$ & $6.80 \%$ \\
\hline 2 & $39.80 \%$ & $42.40 \%$ & $2.60 \%$ \\
\hline 3 & $51.00 \%$ & $59.60 \%$ & $8.60 \%$ \\
\hline 4 & $43.20 \%$ & $54.40 \%$ & $11.20 \%$ \\
\hline 5 & $39.80 \%$ & $38.40 \%$ & $-1.40 \%$ \\
\hline 6 & $36.60 \%$ & $45.40 \%$ & $8.80 \%$ \\
\hline 7 & $36.80 \%$ & $42.60 \%$ & $5.80 \%$ \\
\hline 8 & $39.40 \%$ & $39.40 \%$ & $0.00 \%$ \\
\hline 9 & $39.60 \%$ & $46.40 \%$ & $6.80 \%$ \\
\hline 10 & $50.20 \%$ & $54.00 \%$ & $3.80 \%$ \\
\hline 11 & $35.80 \%$ & $38.60 \%$ & $2.80 \%$ \\
\hline 12 & $43.60 \%$ & $49.80 \%$ & $6.20 \%$ \\
\hline 13 & $34.40 \%$ & $44.20 \%$ & $9.80 \%$ \\
\hline 14 & $42.20 \%$ & $39.80 \%$ & $-2.40 \%$ \\
\hline 15 & $44.40 \%$ & $59.40 \%$ & $15.00 \%$ \\
\hline
\end{tabular}




\begin{tabular}{|l|l|l|l|}
\hline 16 & $39.00 \%$ & $47.20 \%$ & $8.20 \%$ \\
\hline 17 & $33.80 \%$ & $43.00 \%$ & $9.20 \%$ \\
\hline 18 & $27.60 \%$ & $36.60 \%$ & $9.00 \%$ \\
\hline 19 & $48.60 \%$ & $51.80 \%$ & $3.20 \%$ \\
\hline 20 & $49.80 \%$ & $60.20 \%$ & $10.40 \%$ \\
\hline 21 & $43.80 \%$ & $54.40 \%$ & $10.60 \%$ \\
\hline 22 & $37.00 \%$ & $42.40 \%$ & $5.40 \%$ \\
\hline 23 & $50.60 \%$ & $59.60 \%$ & $9.00 \%$ \\
\hline 24 & $43.20 \%$ & $54.40 \%$ & $11.20 \%$ \\
\hline 25 & $38.00 \%$ & $38.40 \%$ & $0.40 \%$ \\
\hline 26 & $35.40 \%$ & $45.40 \%$ & $10.00 \%$ \\
\hline 27 & $36.40 \%$ & $42.60 \%$ & $6.20 \%$ \\
\hline 28 & $35.40 \%$ & $39.40 \%$ & $4.00 \%$ \\
\hline 29 & $41.40 \%$ & $46.40 \%$ & $5.00 \%$ \\
\hline 30 & $50.60 \%$ & $54.00 \%$ & $3.40 \%$ \\
\hline 31 & $36.80 \%$ & $38.60 \%$ & $1.80 \%$ \\
\hline 32 & $41.40 \%$ & $49.80 \%$ & $8.40 \%$ \\
\hline 33 & $34.40 \%$ & $44.20 \%$ & $9.80 \%$ \\
\hline 34 & $42.00 \%$ & $39.80 \%$ & $-2.20 \%$ \\
\hline 35 & $47.40 \%$ & $59.40 \%$ & $12.00 \%$ \\
\hline 36 & $41.20 \%$ & $47.20 \%$ & $6.00 \%$ \\
\hline 37 & $33.60 \%$ & $43.00 \%$ & $9.40 \%$ \\
\hline 38 & $27.40 \%$ & $36.60 \%$ & $9.20 \%$ \\
\hline 39 & $47.80 \%$ & $51.80 \%$ & $4.00 \%$ \\
\hline 40 & $46.80 \%$ & $53.20 \%$ & $6.40 \%$ \\
\hline & & & \\
\hline
\end{tabular}

The above table (no.07) contains the individual marks scored by 40 students at the pre-test and the post-test conducted by the researcher. Five key areas in English vocabulary, punctuation, grammar including capitalization, and knowledge on tenses, and cohesion and coherence were assessed during the test as the basic mechanics required for basic composition skills. According to the analyzed data, students gained a slight improvement in developing basic mechanics required for composition in ESL after the intervention by the researcher as shown above. For instance, 36 ESL students out of the 40 in the sample showed a significant improvement after the intervention period. Only two students showed no change at all before and after the intervention, whereas three students showed a negative reaction in the post-test.

These findings can be discussed in histograms for a more visually comprehensive analysis as follows.

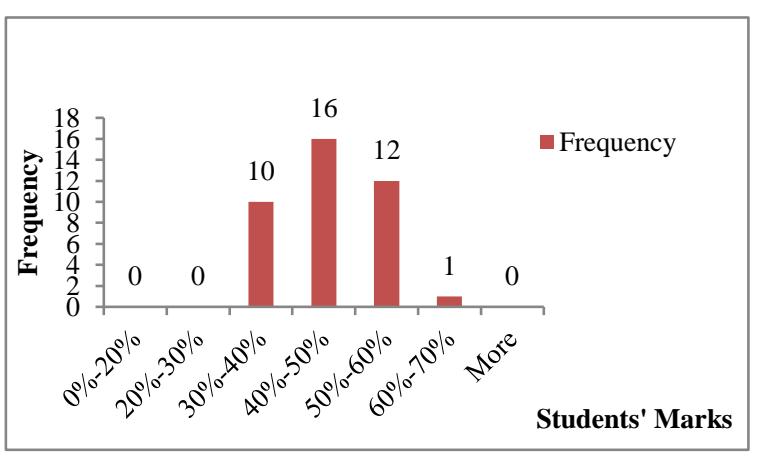

Figure 4. Pre-Test Histogram

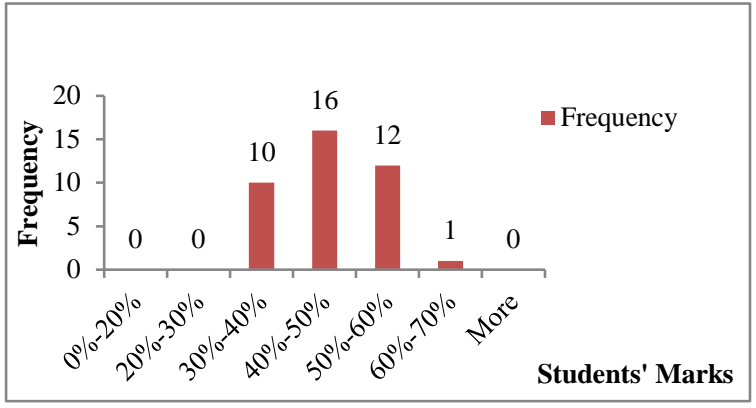

Figure 10. Post-Test Histogram

Thus, Figure 9 and 10 show that the number of ESL students who showed improvement is higher than the ones did not show any sign of improvement. For instance, in the pre-test, only 4 students have scored marks between $50 \%-60 \%$, whereas in the posttest it has increased up to 12 students.

\subsection{Hypothesis Testing}

Individual scores of students were recorded as pretest marks and post-test marks. The mean values of these two data sets were analyzed by using a paired sample T-Test. This test is also known as the 'beforeafter test', since it checks the mean difference before and after a particular experiment, and in the current study it is a pedagogical intervention. In order to carry out a paired sample T-Test, it is essential to identify two variables. Here, the first variable was ESL students' marks for the pre-test while the second variable was students' marks for the post- test. To compare the mean difference of these two variables, the paired T-Test function available in the Microsoft Excel could be used as follows,

Table 5. T-Test statistics

\begin{tabular}{|l|l|r|}
\hline & Variable 1 & Variable 2 \\
\hline Mean & 0.40585 & 0.46945 \\
\hline Variance & 0.003670233 & 0.005204715 \\
\hline Observations & 40 & 40 \\
\hline Pearson Correlation & 0.822789815 & \\
\hline $\begin{array}{l}\text { Hypothesized Mean } \\
\text { Difference }\end{array}$ & 0 & \\
\hline df & 39 & \\
\hline $\mathrm{t}$ Stat & -9.805794134 & \\
\hline $\mathrm{P}(\mathrm{T}<=\mathrm{t})$ one-tail & $2.22304 \mathrm{E}-12$ & \\
\hline $\mathrm{t}$ Critical one-tail & 1.684875122 & \\
\hline $\mathrm{P}(\mathrm{T}<=\mathrm{t})$ two-tail & $4.44607 \mathrm{E}-12$ & \\
\hline $\mathrm{t}$ Critical two-tail & 2.022690901 & \\
\hline
\end{tabular}

According to the above $\mathrm{T}$ statistics table, the generated $\mathrm{T}$ value (Observed) of 4.44607E-12 is smaller than the relevant $\mathrm{T}$ critical value of 2.022690 at the $95 \%$ confidence level. In other words, T observed $<\mathrm{T}$ critical value. According to above statistics, it can be concluded that there is a statistically significant mean difference between the 
pre-test and post-test mean values. Therefore, the initial null hypothesis should be rejected. In other words, it the alternative hypothesis which stated that there is a statistical significant mean difference between Pre-test and Post-Test scores can be accepted. Hence, it is apparent that the researcher's two and half month's intervention sessions were impactful in improving students' basic writing mechanics in developing composition skills of junior secondary L2 learners to a considerable extent.

\section{Conclusion}

In the current study, the main objective was to probe into the grass root level of the issues pertaining to basic mechanics in developing basic composition skills and make improvements via process writing approach using VARK model among junior secondary ESL students in a type C school in Sri Lanka. By identifying the gaps in the field, a sample of 40 ESL students from the grade 10 were selected using convenience sampling. Initial semi-structured interviews were conducted to activate the schemata of some key figures, two ESL teachers and the principal of the school. The researcher could get a comprehensive idea of the circumstances related to teaching and learning of ESL of the sample this way. However, data from the interviews were considered for actual analysis. As tools, structured questionnaires were administered among the 40 students based on their perceptions about basic mechanics of composition writing. A pre-test was given on a suitable topic after which a pedagogical intervention was done with process writing approach via VARK model. Thereafter, a post-test was conducted, and pretest and post- test marks were recorded for analysis via a paired T-test. Participants showed a considerable improvement in applying their composition writing mechanics into their simple compositions. In conclusion, as recommendations, the researcher strongly believes that attempting of new L2 approaches/models or adapting the existing approaches should be more facilitated for the students to practice composition writing, via which they can improve their ESL skills, and receive better grades at classroom and national level exams.

\section{References}

[1] Aikhenvald, A. (2007), Typological distinctions in word - formation, In Language Typology and syntactic description, Ed. By Timothy Shopen, (pp. 1 - 65). Cambridge: Cambridge University

[2] Echevarria, J., Vogt, M.E., \& Short, D. (2004). Making content comprehensible for English learners: The SIOP Fleming, N., \& Baume, D. (2006). Learning Styles Again: VARKing up the right tree! Educational developments, 7(4), 4
[3] Gibbons, P., \& Gibbons, P. (2009). English learners, academic literacy, and thinking: Learning in the challenge zone (pp. 118-130). Portsmouth, NH: Heinemann.

[4] Gottschalk, Katherine and Keith Hjortshoj (2004). The Elements of Teaching Writing: A Resource for Instructors in All Disciplines. New York: Bedford/St. Martin's.

[5] Gunesekara, M (2011), The Post-Colonial Identity of Sri Lankan English, VijithaYapa Publications

[6] Hyland, K. (2003). Second language writing. Cambridge, UK: Cambridge University Press

[7] Leedy, P.D. (2010). Practical Research, Planning and Design 8thEdition. New York: MacMillan Publishing Inc.

[8] Shafie, L. A., Maesin, A., Osman, N., Nayan, S., \& Mansor, M. (2010). Understanding collaborative academic writing among beginner university writers in Malaysia. Studies in Literature and Language, 1(2), 58

[9] Tribble, C. (1996) Writing, Oxford University Press

[10] Wright, S., \& Stokes, A. (2015). The application of VARK learning styles in introductory level economics units. Issues in Educational Research, 25(1), 62

[11] Evaluation Report (2015), G.C.E.(O.L.) Examination 2015: Evaluation Report - 31 English Language, Research \& Development Branch National Evaluation \& Testing Service Department of Examinations

[12] National Institute of Education (2017), English Teacher's Guide: Grade 10, Department of English, National Institute of Education, Maharagama, Sri Lanka

[13] News First (2014), G.C.E O/L Examination: nearly 10,400 fail in all subjects, [Online], Available at: http://newsfirst.lk/english/2014/04/g-c-e-ol-examinationnearly-10400-failed-subjects/28955 [Accessed on: 13th June 2017]

\section{Acknowledgements}

I sincerely acknowledge the guidance given by the University of Kelaniya and Deakin University, Melbourne, Australia for making me what I am today. I am forever grateful to my mentor in research studies: Associate Professor Indika Liyanage, Faculty of Education, Deakin University for enlightening my knowledge on research during the journey of my $\mathrm{PhD}$ (TESOL). Further, I extend my grateful thoughts to my beloved family, baby Evin, and my loved ones who always stand by me whenever I need their shoulder. I cannot forget the things I learnt from Dr Darshana Samaraweera, Department of English, National Institute of Education, Sri Lanka and the sincere moral support given by Ms Jeewani Herath, my PGDE course coordinator, Faculty of Education, University of Colombo. Finally, I thank Mr. Thuseethan Selvarajah, and Ms Nilusha Madhushanthi, my beloved friends at Deakin for 
everything done for me until the publication of this paper! Finally, I am thankful to LICE, 2018 for giving me the wonderful opportunity to have presented this work in their annual conference at the University of Cambridge, U.K. 